\title{
Trabalho coletivo e organização do ensino de matemática: princípios e práticas ${ }^{1}$
}

\author{
Anemari Roesler Luersen Vieira Lopes ${ }^{2}$ \\ Elaine Sampaio Araujo ${ }^{3}$ \\ Wellington Lima Cedro 4 \\ Manoel Oriosvaldo de Moura ${ }^{5}$
}

\begin{abstract}
Resumo: A colaboração de pesquisadores de diferentes instituições em torno do ensino e da aprendizagem da Matemática nos anos iniciais do Ensino Fundamental resultou na organização de uma pesquisa formativa por núcleos em rede, desenvolvida no âmbito do OBEDUC/ CAPES em consonância com os pressupostos da pesquisa colaborativa e da teoria histórico-cultural. Este artigo busca apresentar discussões acerca do fenômeno formação docente e organização do ensino de matemática. A intenção é que estes estudos possam se constituir em indicadores teórico-metodológicos para o processo de aprendizagem docente centrado no modo de produção coletivo. O principal resultado aponta para a importância do compartilhamento do processo de formação em atividades em comum como forma de possibilitar aos sujeitos a oportunidade de desenvolver for- mas específicas de cooperação que venham a favorecer a apropriação do processo significativo da produção coletiva do conhecimento sobre a atividade pedagógica.
\end{abstract}

Palavras-chave: formação de professores, trabalho coletivo, organização do ensino

\section{Collective work and organization of mathematics teaching: principles and practices}

\begin{abstract}
The possibility to bring together researchers from different institutions, with interests focused on the teaching and learning of mathematics in the early years of elementary school has resulted in the organization of a formative research for networked cores. The theoretical background of this work is cultural-historical theory. This article seeks to present the contributions about the teacher education and organization of mathematics teaching. The intention is that results of these studies may constitute theoretical and methodological indicators to the process of teaching and learning centered in the collective production. The main result of this work is the importance of sharing the training process in joint activities as a means of enabling individuals the opportunity of developing specific forms of cooperation,
\end{abstract}

1 Agência financiadora: CAPES/OBEDUC

2 Doutora em Educação pela Universidade de São Paulo em 2004. Professora do Programa de Pós-Graduação em Educação da UFSM e do Programa de Pós-Graduação em Educação Matemática e Ensino de Física da UFSM. E-mail: anemari.lopes@gmail.com

3 Doutora em Educação pela Universidade de São Paulo em 2003. Professora do Programa de Pós-Graduação em Educação da FFCLRP/USP. E-mail: esaraujo@usp.br

4 Doutor em Educação pela Universidade de São Paulo em 20o8. Professor do Programa de Pós-Graduação em Educação em Ciências e Matemática da UFG. E-mail: wellingtonlimacedro@gmail.com

5 Doutor em Educação pela Universidade de São Paulo em 1992. Professor do Programa de Pós-Graduação em Educação da FE/USP. E-mail: modmoura@usp.br 
which will provide appropriation of meaningful process of collective production of knowledge about the pedagogical activity.

Key words: teacher education, collective work, teaching organization

\section{Introdução}

É perceptível a acentuada ampliação, nesta última década, dos debates sobre a formação de professores. Por um lado, isso demonstra a constatação da importância que vem sendo atribuída ao docente como um dos relevantes elementos que fazem parte do processo de ensino e aprendizagem, principalmente nas escolas públicas da Educação Básica. Por outro, ratifica a responsabilidade atribuída a esse trabalhador como um dos principais responsáveis pelos possíveis problemas que possam acontecer nesse âmbito.

Essa dualidade deixa claro que a questão sobre o professor, sua formação e sua atuação não é simples e merece especial atenção por parte das pesquisas e dos estudos, bem como das políticas públicas.

No que diz respeito à formação, em especial na área da Educação Matemática, temos acompanhado diversos trabalhos cujos autores (Fiorentini \& Nacarato, 2005; Lopes \& Curi, 2008; Miguel, 2005; Santos, 2008) apontam para uma compreensão desta como um processo vinculado à prática docente e desencadeador de um movimento que possibilita ao professor a compreensão do seu papel tanto de mediador no processo de ensino e aprendizagem, quanto de gestor de mudanças significativas na sua atividade profissional. Estudos sobre a formação docente que têm como base a Teoria histórico-cultural (Araujo, 2003; Lopes, 2004; Moura, 2000, entre outros) têm assumido a formação docente considerando a atividade de ensino como a unidade formadora do estudante e do professor (Moura, 1996, 2001; Moura, Araujo, Ribeiro, Panossian, \& Moretti, 2010). É nesse espaço conceitual que se localiza o projeto "Educação Matemática nos anos iniciais do Ensino Fundamental: princípios e práticas da organização do ensino", financiado pelo Observatório da Educação (OBEDUC/CAPES), iniciado em 2011 e sob responsabilidade do Grupo de Estudos e Pesquisa sobre Atividade Pedagógica (GEPAPe).

No âmbito desse grupo, a possibilidade de congregar pesquisadores de diferentes instituições e programas de pós-graduação do Brasil, como forma de fortalecer e ampliar linhas de pesquisa da área de Educação Matemática com interesse voltado aos anos iniciais do Ensino Fundamental, resultou na organização de uma pesquisa formativa por núcleos em rede. Assim, o projeto conta com quatro núcleos: dois na Universidade de São Paulo (USP/São Paulo e USP/Ribeirão Preto), um na Universidade Federal de Goiás (UFG) e outro na Universidade Federal de Santa Maria (UFSM). Cada um deles, partindo da intencionalidade de aproximar a universidade 
(pós-graduação e graduação) das escolas de educação básica, se organiza em grupos colaborativos que envolvem professores e/ ou coordenadores pedagógicos de escolas públicas; alunos da graduação e da pós-graduação; e professores universitários.

Assim, considerando o contexto da pesquisa desenvolvida, em consonância com os pressupostos da pesquisa colaborativa assumidos pelo grupo de pesquisa, este artigo busca apresentar as contribuições de estudos realizados por este grupo, orientado pela perspectiva histórico-cultural, acerca do fenômeno formação docente e organização do ensino de Matemática. A intenção é discutir sobre resultados desses estudos como indicadores teórico-metodológicos ao processo de aprendizagem docente centrado no modo de produção coletivo. Para isso, inicialmente trazemos algumas investigações desenvolvidas pelo GEPAPe. Posteriormente, discutimos, com base em resultados de pesquisas vinculadas ao nosso projeto do OBEDUC, o papel de atividades de ensino compartilhadas para a formação de professores na perspectiva por nós adotada. Finalizando, buscamos indicar questões centrais que perpassam a relação entre trabalho coletivo e organização do ensino.

\section{Um olhar sobre a formação docente}

Ao elegermos a atividade de ensino como o elemento basilar da atividade pedagógica, estamos conscientes de que isso exige um esforço para compreender não somente os processos de ensino e aprendizagem, mas também questões relacionadas aos espaços onde esses processos são desenvolvidos.

Tendo como suporte teórico e metodológico a Teoria histórico-cultural, que tem seus fundamentos no materialismo histórico-dialético, o grupo de pesquisa ao qual se vincula o nosso projeto do OBEDUC, nos últimos anos, vem buscando compreender os processos de formação dos indivíduos, sejam eles estudantes, professores ou gestores, participantes de comunidades educativas. Partindo do pressuposto de que a atividade humana é a unidade básica para a compreensão dos processos de desenvolvimento humano, também se entende a educação escolar como um complexo de sistemas de atividades. Diversos trabalhos foram realizados, tendo como princípio norteador o conceito de atividade e, particularmente, o de atividade orientadora de ensino (Moura, 1996, 2001). No decorrer de quase duas décadas, podemos dizer que essas investigações formam dois grandes grupos: aquelas que enfocam a aprendizagem dos estudantes e aquelas que tratam da aprendizagem docente na escola e na universidade.

Como nosso foco de investigação no projeto desenvolvido no âmbito do OBEDUC recai sobre a formação de professores, concentraremos a nossa atenção no segundo grupo de trabalhos, indicando as suas contribuições para o debate em torno dessa questão. Entre essas investigações que tratam da formação do professor, tam- 
bém encontramos dois subgrupos: um grupo que discute os processos de formação continuada do educador na escola e outro que aborda a aprendizagem da docência no âmbito da universidade.

A discussão sobre a formação continuada tem início com o trabalho de Moura (2000). Em sua tese de livre-docência, o autor apresenta os resultados do projeto intitulado “Qualificação do ensino público e formação de professores”. Tendo como principal objetivo investigar as ações que indicavam a construção da coletividade pelo grupo de professores de Matemática de uma escola pública paulista, Moura caracteriza com detalhes a natureza das atividades desenvolvidas na instituição. O principal resultado da investigação indica a necessidade de integrar as ações formadoras, de modo que elas sejam realizadas tendo como base as necessidades assumidas pelo coletivo da escola. Trilhando esse mesmo caminho, Tavares (2002), em sua dissertação, amplia o debate em torno das mudanças qualitativas das ações dos docentes que participaram do projeto. Na sua análise, ela destaca a apropriação e a recriação de instrumentos conceituais pelos participantes e o papel fundamental do compartilhamento das ações pedagógicas, nas suas funções de interpelação dos pressupostos dos professores e de agregação de significado social à atividade de ensino. Em outra dissertação desenvolvida nesse mesmo espaço de investigação, Camargo (2004), uma das professoras da escola pública, parte do projeto supracitado e apresenta os elementos mobilizadores das mudanças qualitativas da prática educativa dos professores de Matemática, após o desenvolvimento de um trabalho colaborativo realizado na escola.

Nas investigações desenvolvidas na escola, Araújo (2003), em sua tese, centra o seu olhar nos modos como o professor da Educação Infantil realiza a sua aprendizagem docente, ao participar de atividades de formação. Nesse sentido, a autora explicita que a possibilidade efetiva de a escola gerar e gerir seus processos formativos acontece somente com o movimento que tem suas origens no próprio terreno escolar e que se caracteriza, necessariamente: pelos modos de organização coletiva; pela explicitação e documentação das práticas; por uma elaboração de instrumentos de trabalho; pela definição de critérios para reflexão; pela mobilização de experiências; e pela mediação cultural.

Por se utilizarem de procedimentos metodológicos semelhantes - o desenvolvimento de cursos destinados à formação continuada do professor de Matemática -, ressaltamos três estudos. O primeiro, de Dias (2007), que enfoca a formação da imagem conceitual; o segundo, de Moretti (2007), que destaca o processo de elaboração de atividades de ensino; e o de Silva (2008), que evidencia a relação entre os educadores infantis e o ensino da Matemática. Esses autores desenvolvem as suas investigações em torno da temática da aprendizagem docente. Em sua tese, Dias 
destaca que o desenvolvimento da imagem conceitual individual de conceito matemático ocorre na relação indivíduo-coletividade e pode ser coerente com o significado científico elaborado historicamente, por meio da realização de uma atividade orientadora de ensino, fundamentada em pressupostos lógico-históricos do conceito. Moretti, em sua tese, chega à conclusão que, por meio da organização coletiva de suas ações, os professores atribuem novos sentidos às próprias ações, à mediação e à escolha de instrumentos, apropriando-se das formas de realização colaborativa da atividade de ensino. Os resultados encontrados na dissertação de Silva mostram que as propostas pedagógicas para Educação Infantil consubstanciadas em um currículo requerem a apropriação do modo de criação de significados do trabalho pedagógico em um contexto denominado por ele como "coletivos de formação".

Desenvolvendo o seu trabalho dentro do projeto intitulado "Oficina pedagógica de Matemática”, o trabalho de Moraes (2008) enfoca o significado da avaliação em Matemática na perspectiva histórico-cultural, ao trabalhar com professores da Educação Infantil e das séries iniciais do Ensino Fundamental. Os resultados dessa investigação evidenciaram que a avaliação constitui constante processo de análise e síntese e seu direcionamento é dado pelo objetivo da atividade de ensino elaborada pelo professor, ou seja, por sua intencionalidade pedagógica.

Compartilhando o objeto de investigação - a avaliação -, mas enfocando o processo de formação do professor na universidade, Barros (2007), em sua dissertação, busca compreender a apropriação desse conceito por parte dos estudantes de Licenciatura em Pedagogia e Matemática, durante o desenvolvimento das atividades do projeto de estágio chamado "Clube de Matemática”. Essa dissertação assinala mais uma vez para a necessidade de oferecer condições para que as ações de formação sejam realizadas colaborativamente.

Nesse mesmo espaço - Clube de Matemática -, Furlanetto (2013), Lopes (2004) e Vaccas (2012) também discutem sobre a formação inicial de futuros professores dos anos iniciais e de Matemática. A principal discussão da pesquisa de Lopes é de que a aprendizagem docente se constitui por meio da mobilização e da apropriação de conhecimentos que permitem mudanças qualitativas das práticas; da mudança dos motivos que desencadeiam as ações docentes; bem como da tomada de consciência sobre os sentidos e significados das ações realizadas durante o projeto de estágio. Vaccas enfoca seu estudo no planejamento e na forma como ele se transforma em ação na atividade educativa, concluindo sobre a relevância do trabalho coletivo para proporcionar situações em que o significado de planejar possa ser apropriado teoricamente pelos sujeitos. Furlanetto investiga o movimento de mudança de sentido pessoal no futuro professor, diante da necessidade de organizar a atividade de ensino na sua formação inicial, concluindo que, embora os sentidos apreendidos 
e em mudança se revelem únicos e pessoais, eles permitem traçar diretrizes para a formação de professores que possam contar com a presença de um mediador pedagógico para subsidiar e organizar a reflexão sobre a organização da atividade de ensino no contexto escolar.

Ainda sobre formação inicial do professor, foram desenvolvidas as teses de Serrão (2004) e Cedro (2008). Serrão analisa a atividade de aprendizagem de estudantes do curso de Pedagogia em um projeto de ensino desenvolvido junto com o Movimento dos Trabalhadores Rurais Sem Terra (MST), tendo como base a perspectiva histórico-cultural. Os resultados do trabalho apontam para a necessidade da criação de condições coletivas para o processo de formação do professor, que permitam aos indivíduos atuarem em outra dimensão humana e com outra qualidade profissional e de pensamento. Cedro discute o processo de transformação e/ ou criação dos motivos na atividade de aprendizagem dos futuros licenciados em Matemática durante o desenvolvimento do estágio supervisionado. Esse estudo indica a necessidade de uma organização de processo de formação do docente que permita não somente a vivência da atividade de ensino, mas a reflexão e a tomada de consciência das suas ações, possibilitando a superação da alienação do sujeito humano diante de si mesmo.

Todos esses trabalhos nos levam a compreender que a atividade de professor é a de quem constrói instrumentos simbólicos para permitir a apreensão da realidade ou a atuação sobre ela num determinado universo cultural. Isso torna a atividade do professor altamente complexa, pois lida com o conceito em seu aspecto mais abstrato: a palavra. As pesquisas citadas mostraram que há um processo de construção de significados, pelos indivíduos, das ações que realizam, sejam eles estudantes ou professores; e que nesse movimento vai se constituindo a aprendizagem da prática pedagógica.

Com a preocupação de oferecer elementos de ordem teórica e prática que contribuam para o processo de aprendizagem da docência, no nosso projeto de pesquisa realizado no âmbito do OBEDUC, balizamos a nossa proposta de formação acadêmico-científica do professor. Ela considera como hipótese primeira que os processos formativos devam não somente possibilitar o reconhecimento e a compreensão das realidades laborais, históricas, culturais e sociais inerentes à prática do professor, mas possibilitar ao indivíduo transformá-las e exercer a condição de sujeito do seu conhecimento, na perspectiva do conhecimento para si e para os outros.

Dessa forma, os processos de formação acadêmico-científicos, a chamada formação inicial, constituem a base para a apropriação do conteúdo inerente à atividade docente. $\mathrm{O}$ modelo que propomos para a formação do professor que ensina Matemática não se baseia em nenhum arquétipo teórico complexo e marcado pela 
inovação; pelo contrário, ele consiste muito mais em mudar a forma de percorrer o caminho que muitos já conhecem. Em outras palavras, nós fizemos uso dos velhos instrumentos teórico-metodológicos para compreender a realidade e inserir os indivíduos em um exercício teórico, político, social e profissional (Serrão, 2004).

\section{Compartilhamento: princípios e práticas}

Ao defendermos o modelo de formação explicitado anteriormente, também assumimos que a aprendizagem é um processo social, e isso tem como decorrência a compreensão de que a interação entre os sujeitos envolvidos possui um papel crucial no seu desenvolvimento. Nessa perspectiva, as ações constituídas coletivamente tornam-se um fator essencial para que o sujeito faça uso de formas de conduta que se encontram no que Vygotski (1997) chamou de Zona de Desenvolvimento Próximo, ou seja, aquelas que ainda não estão desenvolvidas de forma autônoma ou não são usadas de maneira consciente e deliberada. Entendemos, nessa perspectiva, que é por meio do outro que o sujeito pode desenvolver-se; que as funções ainda não dominadas por ele poderão ser internalizadas; e que as formas coletivas precedem as individuais e constituem sua fonte de origem.

O desenvolvimento humano implica a reconstrução interna de uma operação externa. Assim, por exemplo, a criança, com base no aprendizado de um fato externo, aprende por meio da internalização mental e, desse modo, desenvolve-se. Vigotsky (2002) explica que todas as funções no desenvolvimento cultural aparecem duas vezes.

todas as funções entram duas vezes em cena, em dois planos diferentes: primeiro, no social, logo no plano psicológico; primeiro como uma forma de cooperação entre as pessoas, como uma categoria coletiva e interpsicológica, depois como meios de comportamento individual, como uma categoria intrapsicológica. (p. 223)

A ideia aqui apresentada traz implicações tanto relativas ao processo de ensino e aprendizagem voltado ao aluno quanto ao processo de formação do professor que, entendido como contínuo, significa também contínua aprendizagem. Em relação à formação do professor, leva-nos a compreender que a sua qualidade está intimamente relacionada à forma como é organizada, bem como às oportunidades que o docente terá de compartilhar as ações desencadeadas.

O compartilhamento é condição que implica a troca com o outro, a fim de que todos se apropriem tanto das ações desenvolvidas em interação quanto dos sentidos e significados assumidos por elas, gerando um movimento de interdependência entre 
a diversidade dos conhecimentos dos sujeitos envolvidos e a mudança qualitativa tanto das ações quanto dos conhecimentos (Lopes, 2004). Em um grupo, embora as ações sejam de cada um dos sujeitos, aquilo que concretiza sua aprendizagem não acontece a partir do que ele realiza de forma isolada. É a possibilidade de trocar com o outro que vai permitir a cada um dos envolvidos a apropriação dos conhecimentos produzidos coletivamente.

Para Bolzan (2002), o compartilhamento das ações acontece quando a aprendizagem se dá na medida em que as ideias podem ser contraditas, buscando novos sentidos e aprendizagens capazes de romper com modelos aprendidos anteriormente. Afirma, ainda, que o conhecimento pedagógico compartilhado se constrói com base no conjunto de elementos da orientação pedagógica e da constituição do papel do aprender a ser professor. Isso acontece ao desenvolver as ações com outro de forma compartilhada, considerando as possibilidades de aprender na perspectiva do trabalho em conjunto.

A importância do trabalho com o outro é apontada por Rubtsov (1996), que destaca a relevância das ações desenvolvidas com base na interação entre os sujeitos como promotora do desenvolvimento cognitivo. Em relação às crianças, o autor afirma que as suas funções psíquicas superiores "repousam na atividade em comum e desenvolvem-se por interação, transformando-se, então, essas funções nas de cada indivíduo" (p.137).

Sobre o movimento de apropriação de conhecimentos proporcionado pelo compartilhamento de ações, nos pautamos nas palavras de Moura (2011), que diz que "individualmente, cada sujeito da atividade apropria-se, a seu modo, do que foi produzido coletivamente, possibilitando a criação de sentidos que modificam concepções, responsáveis por novas ações, criadas para impactar as realidades simbólicas dos educandos com os quais atua" (p. 95).

Podemos, assim, inferir sobre a relevância do compartilhamento na aprendizagem, destacando que diversas pesquisas, como as de Miskulin et al. (2005), Moraes (2008), Moretti (2007), Vaz, Lopes e Silva (2012), entre outros, reforçam tal importância especificamente nos processos de aprendizagem da docência.

Corroborando tais estudos, apresentaremos dois exemplos, resultantes de pesquisas desenvolvidas no âmbito do nosso projeto do OBEDUC, nos quais o compartilhamento se destacou como um elemento importante na formação de professores que ensinam Matemática.

O primeiro exemplo quem nos traz é Fraga (2013), que investiga o caso de um grupo de estudantes do curso de Licenciatura em Matemática e em Pedagogia, que desenvolviam ações compartilhadas em um projeto com alunos do segundo ano do Ensino Fundamental de uma escola pública. Centra-se especialmente no movimento 
de estudar, planejar, desenvolver e avaliar uma atividade de ensino sobre estatística, mais especificamente, a organização de dados em tabelas, quadros e gráficos. Os momentos de planejamento e organização do material da atividade eram desenvolvidos na universidade e contavam com a participação de todos os envolvidos.

A autora apresenta um episódio ${ }^{6}$, no qual os futuros professores estavam reunidos para discutir as possibilidades de introduzir o conteúdo. Nesse episódio também participam as colaboradoras e a pesquisadora.

Quadro 1: Episódio - Discutindo como introduzir o conteúdo.

Colaboradora Ana - Como vamos introduzir [o conteúdo]?

Pesquisadora - Temos que pensar na necessidade, na síntese histórica!

Olívia - E se a gente montasse uma história pra eles, não dá? Pra contar uma história assim [...].

Colaboradora Ana - Que precisasse desses dados?

Colaboradora Natalie - Já foi difícil assim de fazer a atividade?

Isabela - Não!

Olívia - Desde que eu estou aqui (GEPEMat) não!

Pesquisadora - Cada vez mais ficando mais difícil [...] a gente vai aprimorando. Isabela - Teria que ser uma informação geral?

Pesquisadora - Como assim, uma informação geral?

Isabela - Assim, algum personagem tá tentando montar um jornal [...] daí ele pedia a ajuda deles [...] pra montar este jornal [...] então, a gente podia jogar a informação pra eles irem ajudando. Daí, nós teríamos que pensar se seria só uma informação no geral, ou se, de repente, cada grupo ficasse com uma informação, daí eles decidem o que querem, pode ser até coisas do cotidiano [...] de animais, não sei [...] de times, pode ser entre a turma, talvez [...]

Olívia - Daí eles podem explicar o porquê eles escolheram esse tema.

Isabela - Cada um vai escolher o seu tema!

Olívia - Mas precisa ter a história virtual, sempre?

Colaboradora Natalie - Pode ser uma situação emergente do cotidiano.

Olívia - Daí fica como uma situação emergente.

Juliana - Surge do problema desencadeador.

Colaboradora Ana - Como ela é definida... a situação emergente, é bem amplo este contexto!

Fonte: Fraga (2013, p. 122)

Observa-se que a possibilidade de realizar o planejamento de forma compartilhada permite uma dinâmica de organização em que os estudantes vão apresentando suas ideias, que são complementadas pelos colegas. O problema a ser resolvido nesse momento era comum: como introduzir o estudo sobre estatística para uma turma de segundo ano, tomando-se por base uma situação desencadeadora que permitisse aos alunos apropriarem-se de conhecimentos estatísticos. As

6 O Episódio foi retirado de seus dados coletados durante o acompanhamento do processo de estudo, planejamento, desenvolvimento e avaliação de atividades de ensino, gravados e posteriormente transcritos. 
sugestões partiam de cada um individualmente, mas a solução do problema foi construída de forma coletiva. Nesse caso, lembramos de Moura, Araujo, Ribeiro, Panossian e Moretti (2010, p. 107), ao afirmarem que "o compartilhamento assume o significado da coordenação das ações individuais em determinada situação-problema comum aos indivíduos".

Fraga (2013) destaca que a compreensão de planejamento como elemento organizador da atividade de ensino tem como consequência a premissa de que um planejamento que envolva ações compartilhadas deve garantir que todos os envolvidos compreendam o desenvolvimento de toda a unidade didática relativa a um determinado conteúdo matemático. Por isso, a participação em ações de forma isolada não permite ao sujeito essa compreensão.

Assim, o planejamento, desenvolvido dessa forma, que não só permite, mas exige a participação de todos, concretiza-se como um momento importante para a formação dos futuros docentes, na medida em que lhes permite apropriar-se de conhecimentos relativos tanto à docência quanto ao próprio conteúdo matemático.

Como conclusão, o estudo apontou que as diferentes situações vivenciadas permitiram aos acadêmicos novas aprendizagens. Ressaltou que eles eram de dois cursos diferentes - Pedagogia e Matemática - e, apesar de possuírem conhecimentos de áreas distintas, eram motivados pelos mesmos objetivos, e as divergências e os pontos de vista diferentes não impediam o encaminhamento da atividade - antes, sim, eram propulsores de discussões que oportunizavam novos conhecimentos. Assim, concluiu "que o compartilhamento das ações se efetiva como um elemento importante para a aprendizagem dos futuros professores que ensinam Matemática” (Fraga, 2013, p.127).

Nosso segundo exemplo refere-se ao estudo de Vaz (2013), que objetivou investigar o processo de formação de professoras dos anos iniciais em um grupo que organizava de forma compartilhada atividade de ensino de Matemática para os seus alunos.

A investigação desenvolveu-se em um espaço que tem como condição o desenvolvimento de ações com a participação de docentes universitários e da educação básica; estudantes de pós-graduação em Educação e Educação Matemática, bem como de Licenciatura em Matemática e Pedagogia. O compartilhamento, nesse espaço, é entendido como além do desenvolvimento de ações em conjunto, uma vez que deve permitir a todos os envolvidos a possibilidade de participar de todas as etapas e o comprometimento com essa participação e, nessa perspectiva, tornar-se sujeito da atividade realizada.

Ao refletirem sobre o desenvolvimento de uma atividade de ensino, as professoras se colocaram num movimento de análise do trabalho desenvolvido, conforme 
podemos observar na fala ${ }^{7}$ de uma das docentes - denominada ficticiamente de Susi -, retirada de uma das sessões reflexivas desenvolvidas na pesquisa.

O mais interessante dessa atividade foi a maneira coletiva, colaborativa que nós fizemos aqui no grupo, ... todos estávamos reunidos eu acho que isso foi o diferencial, pois daí nos sentimos comprometidos com todos os passos ... tomar decisões a partir dessa construção coletiva que nós fizemos, nos deu segurança. Deu a todas nós, assim, autonomia para continuar a desenvolver as tarefas em sala de aula. [Professora Susi- Sessão Reflexiva 1]. (Vaz, 2013, p.107)

A referência positiva em relação ao compartilhamento também aparece quando da avaliação sobre a participação no grupo, no decorrer do ano. Cada professora realçou pontos diferentes, mas que permitem relacionar a esse aspecto de que aqui estamos tratando. Uma delas destaca, de forma mais clara, essa condição como estímulo para sua participação. "Foi muito boa a participação, eu gostei muito, achei que a gente divide, a gente discute, a gente opina, a gente vê o que dá para acertar, refletir sobre o que a gente não conseguiu fazer." [Naná- Sessão Reflexiva 1] (Vaz, 2013, p.111).

Para outra participante, o compromisso compartilhado igualmente entre todos os participantes e a voluntariedade foram determinantes.

Eu gostei muito que não existe aquela sobrecarga, aquela cobrança excessiva em cima da gente, todo mundo se compromete, todo mundo faz a sua parte, e o grupo vai andando bem, ... tu vem faceira porque é todo mundo alegre, o grupo é animado. [Carol- Sessão Reflexiva 1]. (Vaz, 2013, p.111)

Tomando por base os dados da pesquisa, a autora destaca que as próprias docentes perceberam uma mudança de qualidade na práxis educativa e a relacionaram com a forma de organização do grupo ao qual pertencem. Ressalta, ainda, que "o comprometimento com o grupo, a troca de experiências e o convívio com diferentes sujeitos contribuíram no trabalho das docentes" (Vaz, 2013, p.117). Essa observação diz respeito a trocas de modos de ação, uma vez que os sujeitos aprendem novas maneiras de desenvolver o trabalho em sala de aula e compartilham suas experiências, adquirindo, através da participação do grupo, novos conhecimentos. Isso foi observado, em especial, nas duas manifestações apresentadas a seguir.

7 As falas aqui destacadas referem-se a duas sessões reflexivas desenvolvidas com a participação das quatro professoras participantes e da pesquisadora, referentes à avaliação do processo de organização de atividades de ensino no qual estavam envolvidas. As cenas foram gravadas e posteriormente transcritas. 
Se não fosse esse comprometimento com o grupo, talvez eu não estivesse estudando como eu estudo, lendo os textos, os referenciais teóricos que o grupo solicita, e mais do que isso, pela primeira vez eu estou lendo não para cumprir uma tarefa, meu motivo é outro, eu leio para ver se eu estou compreendendo, se eu consigo entender melhor aquilo que está colocado. [Susi- Sessão Reflexiva 2]. (Vaz, 2013, p.117)

Isolada tu não tem motivação pra fazer a leitura de um livro, tu não tem motivação pra procurar alguma coisa, agregar ao teu conhecimento, no grupo sempre um está puxando o outro. [Carol- Sessão Reflexiva 2]. (Vaz, 2013, p.117)

De maneira geral, as falas indicam a importância de, ao pensar na atividade pedagógica, fazê-lo no coletivo, nas trocas e na apropriação do conhecimento. Assim, a autora do estudo entendeu que o compartilhamento de ações é um elemento essencial no movimento de formação de professores, pois permite a apropriação dos conhecimentos teóricos e práticos, uma vez que as professoras relatam o quão importante foi a participação no grupo para que pudessem apropriar-se dos fundamentos teóricos que embasam as suas ações. Além disso, sentem-se valorizadas pelos demais participantes, por perceberem que sua participação e os conhecimentos advindos do trabalho docente em sala de aula têm importância na reflexão e são valorizados no desenvolvimento do grupo. Finalizando, Vaz (2013) concluiu que a possibilidade de compartilhar ações permitiu que as professoras estivessem em constante reflexão e aprendizagem.

Com base nos resultados das pesquisas aqui destacadas, compreendemos o compartilhamento como premissa e produto de um projeto coletivo, constituindo-se como um elemento central a ser considerado nos processos de formação tanto inicial quanto continuada.

\section{Da organização do ensino ao trabalho coletivo, do trabalho coletivo à organização do ensino}

O presente artigo objetivou apresentar as contribuições de estudos realizados por um grupo de pesquisa, orientado pela perspectiva histórico-cultural, acerca do fenômeno formação docente e organização do ensino de Matemática, com a intenção de discutir os resultados desses estudos como indicadores teórico-metodológicos ao processo de aprendizagem docente, centrado no modo de produção coletivo. Como explicitamos ao apresentar as pesquisas que desenvolvemos, um dos princípios teóricos básicos que fundamentam a nossa proposta para a formação de professores que ensinam Matemática é o desenvolvimento da compreensão, por parte do indivíduo, da essencialidade do trabalho coletivo. Acreditamos que essas ideias somente 
podem ser apropriadas pelos indivíduos quando possibilitamos a eles situações que solicitem o compartilhamento das ações na resolução de questões que surgem em certo contexto.

Nesse sentido, o compartilhamento assume o significado da coordenação das ações individuais nas situações-problema comuns aos indivíduos. Essa coordenação passa, portanto, pela identificação das características do objeto, pela sua transformação e pela criação de resultados em comum. Logo, o compartilhamento das ações "se manifesta em uma atividade cognitiva produtiva através de um nível elevado de estruturação da atividade intelectual, e num intensificado da reflexão, do controle e da avaliação" (Polivanova, 1996, p. 151).

De forma geral, o compartilhamento das ações é essencialmente baseado no trabalho coletivo e, portanto, presume tanto a cooperação como a colaboração. Lembramos que compreendemos a cooperação como a operação, a execução de determinadas tarefas e atividades vinculadas a certo sistema; já a colaboração presume a produção, o desenvolvimento de ações com base em objetivos comuns. Nesta perspectiva, o trabalho compartilhado deve caminhar, tendo em vista a relação entre a cooperação e a colaboração, pois é na cooperação que encontramos a origem do desenvolvimento intelectual do indivíduo. Graças a ela, o indivíduo pode transformar a maneira como trata o objeto. Ao tomar consciência das relações entre o trabalho cooperativo e o objeto de estudo, a cooperação adquire, então, a forma de modo de ação geral do indivíduo e "torna-se uma espécie de modelo do conteúdo da estrutura cognitiva” (Polivanova, 1996, p. 151).

Nessa ótica, é imprescindível, no processo de formação do professor, criar situações em que haja a necessidade do compartilhamento das ações. Com esses momentos propiciaremos aos indivíduos a oportunidade do desenvolvimento das primeiras formas específicas de cooperação, que permitirão a ele atingir um nível adequado nas ações cognitivas por meio da apropriação e da conscientização do processo significativo da produção coletiva do conhecimento científico.

A possibilidade de diferentes sujeitos - com diferentes conhecimentos - interagirem de modo a permitir o compartilhamento de ações, de seus sentidos e significados, pode ser determinante na mudança de qualidade daquilo que por eles é desenvolvido. Sendo a educação um processo coletivo, é no compartilhar que o docente tem a oportunidade de apropriar-se de novos conhecimentos, pois, embora as ações possam ser de cada um daqueles que concretizam uma determinada atividade, a aprendizagem não acontece no que cada um deles faz de forma isolada, mas na interação entre sujeitos ou entre sujeitos e objetos. Assim, faz-se necessário que as ações sejam desenvolvidas por todos, mas que cada um tenha não só a oportunidade, mas o comprometimento de participar. Dessa maneira, as 
ações não vão se caracterizar como ações individuais, mas coletivas, de tal forma que o trabalho coletivo se apresenta não apenas como premissa, mas, igualmente, como produto, indispensável à formação docente e à organização do ensino, em uma relação dialética na qual a organização do ensino leva à organização do trabalho coletivo, da mesma forma que a organização do trabalho coletivo leva à organização do ensino.

\section{Referências}

Araújo, E. (2003). Da formação e do formar-se: a atividade de aprendizagem docente em uma escola pública. Tese de Doutorado em Educação, Universidade de São Paulo, São Paulo.

Barros, L. (2007). Desenvolvimento do conceito de avaliação na formação inicial de professores em atividade colaborativa. Dissertação de Mestrado em Educação, Universidade de São Paulo, São Paulo.

Bolzan, D. (2002). Formação de professores: compartilhando e reconstruindo conhecimentos. Porto Alegre: Mediação.

Camargo, R. M. (2004). Atividade formadora do professor de Matemática de um projeto em parceria numa escola pública. Dissertação de Mestrado em Educação, Universidade de São Paulo, São Paulo.

Cedro, W. L. (2008). O motivo e a atividade de aprendizagem do professor de matemática: uma perspectiva histórico-cultural. (242 pp.). Tese de Doutorado em Educação, Universidade de São Paulo, São Paulo.

Dias, M. (2007). Formação da imagem conceitual da reta real: um estudo do desenvolvimento do conceito na perspectiva lógico-histórica. (252 ff.). Tese de Doutorado em Educação, Universidade de São Paulo, São Paulo.

Fiorentini, D., \& Nacarato, A. M. (Orgs.) (2005). Cultura, formação e desenvolvimento profissional de professores que ensinam matemática. São Paulo: Musa.

Fraga, L. P. (2013). Futuros professores e a organização do ensino: o Clube de Matemática como espaço de aprendizagem da docência. Dissertação de Mestrado em Educação, Universidade Federal de Santa Maria, Santa Maria, RS.

Furlanetto, F. R. (2013). O movimento no sentido pessoal na formação inicial do professor. Tese de Doutorado em Educação, Faculdade de Educação, Universidade de São Paulo, São Paulo.

Lopes, A. R. L.V. (2004). A aprendizagem docente no estágio compartilhado. Tese de Doutorado em Educação, Universidade de São Paulo, São Paulo.

Lopes, C. E., \& Curi, E. (Orgs.) (2008). Pesquisas em Educação Matemática: um encontro entre a teoria e a prática. São Carlos, SP: Pedro \& João Editores.

Miguel, A. (2005). História, Filosofia e Sociologia da Educação Matemática na formação dos professores: um programa de pesquisa. Educação e Pesquisa, 31(1), 137-152.

Miskulin, R. G. S., Nacarato, A. M., Passos, C. L. B., Lopes, C. A. E., Fiorentini, D., Brum, E.D., ... Grando, R. C. (2005). Pesquisas sobre trabalho colaborativo na formação de professores de matemática: um olhar sobre a produção do Prapem/Unicamp. In: D. Fiorentini, \& A. 
M. Nacarato (Orgs.), Cultura, formação e desenvolvimento profissional de professores que ensinam matemática (pp.196-216). São Paulo: Musa.

Moraes, S. G. (2008). Avaliação do processo de ensino e aprendizagem em Matemática: contribuições da teoria histórico-cultural. Tese de Doutorado em Educação, Universidade de São Paulo, São Paulo.

Moretti, V. D. (2007). Professores de matemática em atividade de ensino: uma perspectiva histórico-cultural para a formação docente. Tese de Doutorado em Educação, Universidade de São Paulo, São Paulo.

Moura, M. O. (1996). A atividade de ensino como unidade formadora. Bolema, 2(12), 29-43.

Moura, M. O. (2000). O educador matemático na coletividade de formação: uma experiência com a escola pública. Tese de Docência em Metodologia do Ensino de Matemática, Universidade de São Paulo, São Paulo.

Moura, M. O. (2001). A atividade de ensino como ação formadora. In: A. D. Castro, \& A. M. P. Carvalho (Orgs.), Ensinar a ensinar: didática para a escola fundamental e média (pp. 143162). São Paulo: Pioneira Thompson Learning.

Moura, M. O. (2011). A aprendizagem inicial do professor em atividade de ensino. In: A. R. L.V. Lopes, M. T. C. Trevisol, \& P. S. Pereira (Orgs.), Formação de professores em diferentes espaços e contextos (pp. 87-102). Campo Grande, MS: Editora UFMS.

Moura, M. O., Araujo, E. S., Ribeiro, F. D., Panossian, M. L., \& Moretti, V. D. (2010). A atividade orientadora de ensino como unidade entre ensino e aprendizagem. In: M. O. Moura (Org.), A atividade pedagógica na teoria histórico-cultural (pp. 81-109). Brasília: Líber Livro.

Polivanova, N. (1996). Particularidades da solução de um problema combinatório por alunos em atuação de cooperação. In: C. Garnier, N. Bednarz, \& I. Ulanovskaya (Orgs.), Após Vygotsky e Piaget: perspectiva social e construtivista. Escola russa e ocidental (Eunice Gruman, trad., pp. 151-159). Porto Alegre: Artes Médicas.

Rubtsov, V. (1996). A atividade de aprendizado e os problemas referentes à formação do pensamento teórico dos escolares. In: C. Garnier, N. Bednarz, \& I. Ulanovskaya (Orgs.), Após Vygotsky e Piaget: perspectiva social e construtivista. Escola russa e ocidental (Eunice Gruman, trad., pp. 129-137). Porto Alegre: Artes Médicas.

Santos, V. M. (2008). A matemática escolar, o aluno e o professor: paradoxos aparentes e polarizações em discussão. Caderno CEDES, 28(74), 25-38.

Serrão, M. (2004). Estudantes de Pedagogia e a "atividade de aprendizagem": do ensino em formação. Tese de Doutorado em Educação, Universidade de São Paulo, São Paulo.

Silva, S. M. (2008). Matemática na infância: uma construção, diferentes olhares. Dissertação de Mestrado em Educação, Universidade de São Paulo, São Paulo.

Tavares, S. C. A. (2002). A profissionalidade ampliada na atividade educativa. Dissertação de Mestrado em Educação, Universidade de São Paulo, São Paulo.

Vaccas, H. L. (2012). A significação do planejamento de ensino em uma atividade de formação de professores. Dissertação de Mestrado em Educação, Universidade de São Paulo, São Paulo.

Vaz, H. G. B. (2013). Formação de professoras dos anos iniciais: a organização do ensino de matemática. Dissertação de Mestrado em Educação, Universidade Federal de Santa Maria, Santa Maria, RS. 
Vaz, H. G. B., Lopes, A. R.L.V., \& Silva, D. S. G. (2012). Dimensão colaborativa no movimento de ensinar, aprender e formar-se professor que ensina matemática. Roteiro, 37(1), 127-146.

Vigotsky, L. S. (2002). A formação social da mente: o desenvolvimento dos processos psicológicos superiores. São Paulo: Martins Fontes.

Vygotski, L. S. (1997). Obras escogidas V. Madrid: Visor.

Submetido em: 22/01/2016

Aceito em: 09/02/2016 